\title{
PSICOTERAPIA DURANTE A PRIMEIRA CONSULTA
}

\author{
VIRgflio CAMARgo PACHECo *
}

Geralmente os neuropsiquiatras são procurados, em consultório, por pacientes que têm tudo a lucrar com uma convivência assídua e prolongada com o especialista. Este terá, então, oportunidade de estudar, em superfície e em profundidade, a personalidade total do paciente, antes de instituir uma terapêtica pluridirecional e ajustar, a cada caso particular, uma diretriz psicoterápica, ou mesmo, em certos casos, indicar a psicanálise. $\mathrm{Na}$ prática, no entanto, não ultrapassa talvez de $10 \%$ o número de consulentes que tenham oportunidade, por vários motivos (dificuldade de locomoção, perda de horas de serviço, falta de tempo do especialista, questões de ordem financeira, incompreensão por parte dos clientes das vantagens dessa convivência) de estar em contacto mais ou menos prolongado com o profissional. Calculamos que cêrca de $50 \%$ dos consulentes dos neuropsiquiatras são vistos pelo especialista apenas uma primeira e única vez. Ora, sabendo-se o valor inconteste do complemento psicoterápico em tôda orientação terapêutica $\mathrm{em}$ nossa especialidade, e partindo do são princípio de que o cliente deve tirar o máximo resultado dessa primeira consulta, devemos aproveitar, quando possível, o quarto de hora que dedicarmos a essa psicorapia.

Um dos erros mais freqüentes e de conseqüências deploráveis, cometidos pelos familiares do paciente, pelos seus amigos e não raro confirmados pelo médico da família e que deve ser desfeito enèrgicamente pelo neuropsiquiatra, é o cometido quando se quer provar ao neurótico que sua cura está exclusivamente em suas mãos, que não tem nada, que só lhe falta "reagir" para ficar completamente bom. Devemos lembrar, a êste respeito, que o paciente adulto, homem ou mulher, antes de confessar abertamente sua sintomatologia neurótica, por exemplo, que tem receio de saír à rua

Trabalho apresentado à Secção de Neuro-Psiquiatria da Associação Paulista de Medicina em 6 setcmbro 1946. Entregue para publioxção em 6 setembro 1946.

* Diretor clínico do Sanatório Bela Vista (S. Paulo). 
Uesacompanhado, de ficar sofrendo dos pulmões, de estar contaminado pelo bacilo de Hansen, de morrer de repente, de estar ficando louco, de numa impulsão matar uma criança - já lutou com tôdlas as fôrças para dominar-se, para controlar seus obcessões, compulsão e fobias. Portanto, quando chega a externar, sem rebuços, tudo o que sente, já esgotou pràticamente o poder de reação, ou melhor, de autolomínio. Instigar tais pacientes a reagir a todo preço, sem prèviamente serem submetidos a orientação racional, é submetê-los a constante e inútil martírio, a renovadas humilhações diante de si mesmos, e incitá-los, além do mais, a gastar inglòriamente, sem probabilidade de êxito, as últimas energias que lhes restam e que noderão ser melhor aproveitadas. Nestas circunstâncias, devemos demonstrar aos acompanhantes do consulente e a êste próprio, que sòmente submetendo-se à orientação especializada, com método $\epsilon$ aos poucos, é que conseguirá ir readquirindo o domínio de si mesmo, irá reagindo com eficácia contra a sintomatologia que tanto o faz sofrer.

Outro hábito, também generalizado e bastante maléfico, cometido pelos que convivem com o paciente, é provar a êste, a todo o instante, que tudo o que sente e de que se queixa não tem base real, sendo exclusivamente devido ao fato de' ser êle "nervoso". Como o vocábulo "nervoso" tem, na acepção popular, um sentido sob certos aspectos pejorativo e depreciativo, sendo empregado por vezes como sinônimo de pusilanimidade, de carência de energia, mesmo de falta de coragem para enfrentar a vida $\mathrm{e}$ as situações difíceis, o indivíduo, ao cabo de certo tempo, acaba crente que de fato é um fracassado, um inútil sem probabilidade de recuperação. Começa então a adquirir hábitos de vida singulares, a contornar os obstáculos, dando rodeios, em vez de encará-los de frente. a adotar um modus vivendis em que procura adaptar sua vida à neurose, com perigo de cristalização definitiva da sintomatoiogia apresentada.

O especialista, quando isto acontece, deve-se insurgir enèrgicamente contra esta absurda concepção, demonstrando ao cliente é, s’ possível, aos seus familiares, que absolutamente não é um nervoso, de acôrdo com esta interpretação popular, mas apenas está sofrendo de um desajustamento temporário do sistema nervoso, desajustamento de que não se deve acanhar, pois é perfeitamente comparável a um desarranjo para o lado do aparêlho respiratório, circulatório ou digestivo, e suscetível, portanto, de regredir com uma orientação terapêtutica bem ajustada. Esta orientação aparcntemente banal costuma dar muito bons resultados, pois, a menos que se trate de um caso especial - como, por exemplo, quando o 
doente se refugia na neurose, por assim dizer de maneira voluntária, - via de regra o paciente sente-se bem e mais confortado quando o elevamos, diante de si mesmo e da sua "entourage", de simples "nervoso" à categoria de um doente comum, que pode ser tratado com suresso pelo arsenal terapêutico ao alcance do especialista.

Outro ponto importante, na primeira consulta, para o qual, aliás, chamam a atenção os tratadistas, é sondar, antes de instituirmos nossa terapêutica, como o paciente julga que seu tratamento leve ser conduzido. Assim, por exemplo, se pensa que preliminarmente deve fazer uma، radiografia do crânio, uma reação de Wassermann no sôro sangüíneo, um eletrocardiograma ou mesmo uma intubação duodenal, ou ainda quer fazer, concomitantemente com nosso tratamento, hidroterapia ou submeter-se a aplicações de cori entes galvânicas ou farádicas, devemos ter muito cuidado em combater intransigentemente tais pretensões, mesmo que não haja indicação formal para ela. Devemos lembrar-nos de qua é pouco provável que consigamos reformar, em poucos minutos, convicções lentamente amadurecidas no espírito do cliente. Nossa insistência «m fazê-lo mudar ràpidamente de opinião, via de regra só consegue abalar a confiança com que veio à nossa consulta e conseqüentemente procurar outro médico que o "compreenda" melhor. Um bom critério, nestas circunstâncias, é instituir nossa terapêtitica, razendo "vista grossa" no sentido de o consulente ficar com a possibilidade de associar a ela suas pretensões, desde, está claro, que não sejam nocivas ao doente ou colidam com nossa orientação.

Em 1943 tivemos, em consultório, P. B., rapaz de certa instrução, de 29 anos, que apresentava desenvolvimento dos músculos peitorais algo exagerados, certo acúmulo de ádipe nos quadris, sistema piloso do tipo feminino, apesar do que, não havia o menor indício de inversão dos instintos sexuais e o paciente conservava tendências e inclinações tipicamente masculinas. Apenas queixava-se de que, nos últimos meses, as erecções eram mais preguiçosas e a ejaculação um tanto precoce, isso certamente influenciado psiquicamente, do menos em parte, pelo seu biotipo que o desagradava bastante. Confessou, logo de início, que nos viera procurar principalmente para que indicássemos como deveria fazer para conseguir o seu perfil endócrino e, à vista do mesmo, autolisados glandulares, pois um seu amigo. versado em questốes de medicina, lhe assegurara que essa era a terapêutica essencialmente adequada ao seu caso. De nossa parte, procuramos provar-lhe que essa não era a terapsutica que the convinha, pois, entre outros motivos, a verif:cação do perfil endócrino vinha caindo em desuso, desde que se provou não corresponder na prática. O paciente, no entanto, insistiu no seu ponto de vista c nós no nosso, até que, ao cabo de meia hora de troca de idéias, pareceu render-se a final à ncssa argumentaçãc, prcmetendo seguir à risca nosso tratamento. Passados dois ou três meses, encontrâmo-lo casualmente na rua. Veio logo ao nosso encontro com ar triunfante, todo lépido e fagueiro, contando-nos, sem mais preâmbulos, que tinha afinal seguido sua própria orientação; fizera o perfil endócrino vinha tomando os lisados que, segundo sua opinião, estavam dando resultados surpreendentes! 
Momento crucial da primeira consulta é quando o consulente e, por vezes, as pessoas que o acompanham, nos transformam de examinadores em examinados, ao procurarem fazer sondagens a fim de verificar se estamos absolutamente convencidos da possibilidade do desaparecimento completo e definitivo da sintomatologia mórbida que tanto molesta o cliente. Grande número de pessoas que procuram os neuropsiquiatras, principalmente as de nível intelectual pouco elevado, chegam a pretender, juntamente com seus familiares, que lhe sejam dadas garantias de que vão ficar radicalmente curadas, indagando mesmo, por vezes, em quanto tempo isso se dará. Trava-se, então, rápida mas encarniçada esgrima mental entre o consulente e o especialista; a menor hesitação nas respostas dêste último poderá comprometer inteiramente sua atuação neste primeiro contato com o paciente. Se o profissional assegurar com veemência que o restabelec:mento do cliente se fará definitivo e integral, além do aspecto anticientífico de tal afirmativa, assumirá grande responsabilidade, pois pode tratar-se de uma neurose maligna ou mesmo de psicose severa, oculta, inicialmente, por uma cortina de fumaça de colorido neurótico. Podemos, com isso, causar uma série de malefícios não só ao próprio doente como também a seus familiares e até estranhos, que podem ser afetados por tal afirmativa. Assim é que, por exemplo, de acôrdo com o que dissermos de maneira categórica, o paciente irá ou não entabolar uma operação comercial de vulto, abandonar ou não os estudos, ou mesmo, decidir-se ou não por um casamento, enfim, tomar resoluções suscetíveis de repercutir intensamente tanto no seu, como no futuro de outras pessoas. Por outro lado, à menor vacilação de nossa parte, à menor suspeita de que o que estamos dizendo em prol de um próximo restabelecimento não exprime nossa conviç̧ão íntima $\mathrm{e}$ visa armar efeito sugestivo tão sòmente, grande parte do valor da consulta esvai-se instantâneamente, pois é sabido que o neurótico é extremamente desconfiado e impressionável.

Temos procurado várias fórmulas para sairmos airosamente desta prebenda, beneficiando ao mesmo tempo o consulente. Nestes últimos tempos temos adotado, com bastante sucesso, a seguinte maneira de agir: fazemos sentir aos pacientes que a resposta às suas indagaçōes quanto à cura divide-se em duas partes. Pela primeira, que se baseia nos recursos terapêuticos aplicáveis ao caso particular, pode o neuropsiquiatra responsabilizar-se pela eficácia, cabalmente satisfatória, de sua atuação. Pela segunda, no entanto, tão importante como a primeira e que se fundamenta na confiança que o cliente depositar no especialista, pelos repetidos contactos que deverá ter com êste e pelo cumprimento rigoroso de suas determinações, terá que responder o próprio consulente. Dessa maneira, não concorremos, mesmo em parcela mínima, para diminuir a esperança do paciente na recuperação integral de seu equilíbrio nervoso e, ao mesmo tempo, na hipótese de não voltar mais à nossa consulta, temos ressalvada nossa responsabilidade. Se voltar, 
teremos oportunidade, uma vez conquistada a confiança do paciente, de adotar a picoterapia mais adequada ao caso concreto.

Feitas estas consıderações de ordem geral, vejamos quais os elementos que precisamos possuir, para adaptar a cada cliente a psicoterapia suscetíve de ser feita na primeira consulta. Para isso, precisamos conhecer certos principios dimanados das mais recentes tendências psicopatológicas. Primeiramente, vejamos alguns dêles que se relacionam com a fenomenologia, que tem seus máximos representantes nos autôres de língua alemã. Estes princípios se orig nam da impossibilidade na qual veio a se achar o racionalismo das ciências naturais, de explicar as relações existentes entre os fatos psíquicos e também do fracasso do atomismo. Tais os motivos que levaram a consilerar o homem em sua totalidade, un e indivisível portanto, e a estudar a psicologia por uma intuição imediata que apreendia as "coisas mesmas" de maneira global, conjuntiva. Sôbre êste ponto de vista é que Jaspers e Binswanger insistem com referência à distinção que se deve fazer entre os motivos que se aplicam aos fatos psíquicos e aquêles que dizem respeito às ciências naturais. Isso porque, enquanto êstes últimos dissecam os fatos, um por um, depois de tê-lo isolado de "seus conjuntos" para em seguida estudar as relações que existem entre êles, conforme os princípios de causalidade, os fatos psíquicos são acessiveis de maneira bem diferente. Eles constituem conjuntos, ou totalidades indivisíveis, sôbre o que vem insistindo a Gestaltpsychologie. Esses conjuntos, vividos intensamente pelos pacientes, constituem os momentos vitais e podem, em certos casos, ser acessíveis ao especialista por uma intuição imediata e ao mesmo tempo racional. $\mathrm{O}$ esfôrço que êste faz para compreender êstes conjuntos não de maneira estát:ca mas procurando ter dêles uma compreensão genética, pondo-se ao par, o mais ràpidamente possível, dos liames pelos quais se ligam estas vivências, constitui seu escopo máximo na primeira consulta.

Esta noção de compreensibilidade dada pela escola fenomenológica, pela qual se procura entender os acontecimentos como foram vividos e não como deveriam ter sido vividos, é de importância fundamental para podermos apreender ràpidamente, no curto tempo de uma consuita, a gênese sintímica básica da sintomatologia que trouxe o paciente a nossa presença. Assim é que podemos compreender, em muitos casos, se a sintomatologia tem fundamento principal num processo holotímico, o que se ver:fica quando um estado efetivo intenso supervaloriza diterminadas vivências, fazendo com que elas repercutam associativamente e com grande ressonância sôbre outras representações psíquicas. Dessa maneira, costumam adquirir extraordinária imṛortância no pensamento do doente, fatos insignificantes tais como pequenas negligências, esquecimentos, êxitos, e aborrecimentos de ordem profissional ou ética.

Pelo estudo fenomenológico, que se esforça por compreender os acontecimentos psíquicos como são vividos pelo paciente sem apelar para considerações teóricas complicadas - o que se relaciona até certo ponto 
com a filosofia do ex̧istencialismo - pode-se chegar a entrever como "o Eu e o Mundo" aparecem ao indivíduo observado. Esta compreensão tem lugar de diferentes maneiras. Pode ser imediata, à custa de um mecanismo intuitivo que Jaspers, Binswanger e Minkowsky chamam E.nfühlung (interpenetração afetiva), felo qual consegue-se ter idéia à primeira vista, de certos tipos de personalidade mórbida, tal, por exemplo, um maníaco-depressivo, tanto em fase maníaca como melancólica, de cujo estado afetivo podemos tomar conhecimento diretamente, sem necessidade de procurarmos reproduzir em nós mesmos, por analogia, uma representação dos sentimentos experimentados pelo paciente. Outro mecanismo de compreensão, que costuma ser tambem rápido, embora se base:e ainda, em boa parte, numa penetração afetiva, que procuramos fazer no $\mathrm{Eu}$ do paciente, necessita contudo de certo raciocínio, de certa identificação com o consulente, com que procuramos nos inteirar das relações tanto atuais como passadas, entre êle e o mundo. Este mecanismo de compreensão é, por conseguinte, afetivo e ao mesmo tempo racional.

Esta é a maneira de compreensão que podemos usar na primeira consulta, para procedermss à rápida psicoterapia adaptada ao caso part:cular de cada consulente. Isso porque, devido a certa concordância entre os dados contínuos que observamos em nós mesmos e os dados descontínuos percebidos no paciente, nosso raciocínio consegue estabelecer. muitas vezes, um laço inteligível entre as vivências dêstes últimos e perceber qual a que está supervalorizada e repercutindo desfavoràvelmente sôbre uma esfera de influência mais ou menos extensa. Tal o caso de:

M. P., senhora de 37 anos que nos consultou em 1942. Contava que seus padecimentos datavam de seis meses e se iniciaram logo após ter sido acometida de disenteria amebiana. Uma vez debelada esta e normalizadas as funçōes intestinais, começou a sentir ansiedade difusa, que foi crescendo assustadoramente a ponto de fazê-la, por vezes, gritar de desespêro. Essa ansiedade foi em seguida mitigandosc: e traduzindo-se por manifestações somáticas tais como sensação de apêrto na garganta, palpitações, sensação de cansaço extremo e de constricção na fronte, le insegurança, de pêso no estômago. Havia já consultado vários médicos que diziam qưc ela nada mais sofria, que estava apenas nervosa, que precisava tão sòmente "reagir" para sentir-se completamente bem. Ela, no entanto, não se conformava com êsse raciocínio simplista, em primeiro lugar porque já tinha tentado "reagir" c, em segundo, porque nunca tinha sido nervosa ou impressionóvel, e nem tinha ascendentes com passado neurótico. Nessas circunstâncias, estava começando a julgar que sua doença não se encontrava ao alcance dos recursos dínicos de investigação e que, talvez, com a ameba, tivesse proliferado outro parasita ou germe desconhecido ainda dos médicos, ou, o que era pior, talvez houvesse algo de misterioso e sobrenatural no seu caso.

Partindo do princípio de que havia no caso um componente psicógeno bastante séric, apuramos a anamnese e, depois de algumas dificuldades, pois a doente manifestava certa relutância a respeito, conseguimos saber que há pouco mais de um ano havia mudado de residência, indo morar em cidade do interior, e que essa mudança fôra decretada pelos contratempos financeiros do marido. Essa ocorrência contrariou-a muitíssimo, mesmo porque fôra obrigada, pelo mesmo motivo, 
a tirar dois filhos dos estudos, um dos quais já era ginasiano. Quando sobreveio o surto amebiano, no seu entender, já estava conformada com a situação, motivo yelu qual não julgou que êsse fato tivesse relação com a neurose atual. Foi-nos tácil explicar à paciente que essa situação destavoravel, essas aspirações frustadas c suportadas resignadamente, enquanto suas condições de higidez somática sram perfeitas, vieram entretanto à tona, sob forma neurótica, logo que sua resistencia física decaiu. Fizemos, em seguida, ligeira explanação sôbre a fixação sumática da ansiedade difusa que sentiu inicialmente, produzindo a sintomatologia que a trouxe à nossa presença. Essa explicação foi aceita com satisfação pela consulente quc, logo em seguida, nos declarou sentir-se mais aliviada e confortada, eis que encontrara quem havia entendido seu caso, que já não lhe parecia tão estranho e misterioso.

A grande maioria dos pacientes que procuram neuropsiquiatras almejam, mais que tudo, encontrar quem os entenda e explique a gênese de sua doença. Para o conseguir devemos mostrar-nos interessados nas queixas e na descrição pormenorizada que fazem de seus sintomas, mesmo que estejamos convencidos de que a maioria dêles não contribui para a elucidação do caso; ao mesmo tempo, devemos evitar asseverar-lhes que tais sintomas não têm importância, que são efeito e não causa da neurose. Devemos evitar dizer-lhes simplesmente, sem mais pormenores, que se trata de uma neurose compulsiva, de uma síndrome neurasteniforme, de uma histeria de convarsão ou de uma distonia neurovegtativa. Essa técnica, "pour épater", só concorre, na grande maioria dos casos, para aumentar a preocupação dos consulentes e fazer com que procurem outro especialista ou mesmo que demandem outros recursos extramédicos. Ao contrário, ouvindo com paciência as queixas dos clientes, temcs mais elementos para encontrar o fio da meada; assegurando que o que o consulente disse foi muito importante e concorreu sobremaneira para que pucéssemos resolver o caso com eficiência, ganhamos de início sua simpatia, condição preliminar indispensável para qualquer tentativa uıterior psicoterápica.

Ao lado disso, o sspecialista deve ter presente ao espírito outro princíp.o fundamental da moderna psiquiatria dinâmica: deve lembrar-se que as tensões emotivas prolongadas, intensas e de tonalidade desagradável podem traduzir-se por manifestações somáticas e que tais manifestações são comumente precedidas por um estado intermediário ansioso, sabido que a ansiedade, fonte dinâmica de muitas neuroses, costuma sobrevir quando os indivíduos não conseguem resolver, por outros mecanismos de defêsa, seus conflitos internos, seus recalques e aspirações frustadas. Desenvolve-se, então, a síndrome ansiosa que, ao cabo de certo tempo, vai-se mitigando à medida que começa a traduzir-se por manifestações somáticas tais como palpitações, distúrbios da respiração, sensação de constrição da garganta e do tórax, rubor súbito, transpiração excessiva, tremores, sensação de fraqueza aparentemente inexplicável. Não raramente tudo isso é acompanhado de sensação difusa, informulada mas intensa, de um receio vago, indefinido, com ou sem colo- 
rido obcessivo. Massermann, ao descrever êste quadro das manifestações. somáticas da ansiedade, assinala que a linguagem usada por tais pacientes é variável quando descrevem seus sintomas, mas pode-se em geral perceber que os que sofrem estas reaçóes ligadas a fôrças emotivas represadas, sentem alívio quando, por qualquer motivo, tais fôrças tensionais diminuem.

Convém estarmos ao par da possibilidade de que essas tensões enıcionais geradoras de síndromes ansiosas podem aumentar ainda mais a ansiedade, quando o poder repressivo, baseado no autodomínio, é ameaçado, como por exemplo durante as tentações sexuais, quando as fobias são transgredidas como no caso de um claustrofóbico ser obrigado a permanecer num recinto ou quando o ritual defensivo do neurótico que lava e desinfeta as mãos constantemente, por qualquer motivo, não pode ser levado a cabo.

O especialista não deve esquecer que os estados emotivos podem encontrar expressão em sintomas somáticos, diretamente, sem passar por um estado ansioso intermediário. Convém lembrar-lhe que simbólicas disfunções corporais difusas e subagudas, muitas vezes são de origem neurótica, constituindo as organoneuroses e que tais disfunções têm tendência a se cronificar, desde que os conflitos reprimidos que thes deram origem não sejam descobertos e removidos. Tal o motivo, por exemplo, de certas úlceras gástricas poderem ser curadas pela psicanálise.

Necessita, finalmente, o especialista estar atento, a fim de não dsixar despercebidos certos sintomas de conversão para o lado sensoriomotor, tais como certas amauroses, surdez e paralis:as de fundo histeriforme, conversões essas que, por vezes, acalmam completamente a síndrome ansiosa, dando mesmo a impressão de terem resolvido o estado emotivo. Ainda há pouco tempo, tivemos em consultório um caso desta ordem:

O. M., casada, com 39 anos de idade, que sempre teve tendência ao misticismo e inclinação irrefreável para a vida religiosa. Sua aspiração máxima sempre foi tornar-se freira, mas há vários anos casou-se, premida pela família que a forçarz a isso. Apesar de seu marido sempre ter-se mostrado bom e compreensivo, tem vivido em constante ansiedade, que nor vezes se alterna com surtos de cegueira, de anartria, de paralisias passageiras. E de notar que essas conversões sensoriomotoras resolvem tão bem a ansiedade da paciente, que esta durante tais períodos, encara. êsses fenómenos de conversăo, com a displicência que Janet chamou "la belle indifference".

De posse dêsses elementos e levando em conta os dados obtidos pela anamnese que informam não sòmente sôbre a história da doença $e$ antecedentes pessoais e hereditários como sôbre o nível intelectual e educacional do consulente, sôbre o meio em que vive e sôbre possibilidade da existência de estado autotóxico ou toxinfeccioso concomitante e, ainda, dando o devido valor ao conceito a que se refere Krainer quando diz 
que a personalidade total é função da unidade sociopsicobiológica numa dada situação e num dado tempo, podendo ser compreendida sòmente se estudada como tal, estamos aparelhados para fazer uma psicoterapia eficiente já durante a primeira consulta.

Resta sòmente sintonizar nosso $\mathrm{Eu}$ contínuo com o $\mathrm{Eu}$, para nós descontínuo, do paciente, procurando identificar-nos rápidamente com sua maneira de ser e de reagir às circunstâncias e situações desfavoráveis para, afinal, entendermos o consulente, vivermos com êle seu atual mom $=n t o$ vital e ligarmos por um liame compreensível as vivências relacionadas com a sintomatologia atual. Desde que consigamos chegar a êste ponto, não será difícil dar ao cliente uma explicação satisfatória do mecanismo íntimo do desajuste psíquico que apresenta. Essa explicação, em muitos casos, será suficiente para destruir o pensamento mágico que dormita no âmago do Eu profundo de todos nós, mas que, acordado, vem à tona e predomina sôbre o pensamento lóg:co, tôda vez que sentimos nossa integridade somática, mental ou mesmo somatopsíquica, ameaçada por uma causa que não sabemos qual seja e da qual ninguém nos dê uma expl:cação compreensível e convincente.

Uma vez consolidada a confiança no especialista e reposto o pensamento lógico em seu devido lugar, há uma sedação considerável e for vezes imediata da ansiedade e dos sintomas dela decormentes, É óbvio notar que, mesmo con êsses elementos que vimos passando em revista, não podemos; no rápido tempo de uma consulta, dar sistemàticament? com a pista que nos permita fazer uma psicoterapia consentânea com os dados clínicos apresentados por todos consulentes. Haverá certamente casos mais complexos, nos quais sòmente após várias sessões chegaremos a penetrar o sentido e a gênese dos sintomas ou para a reso-

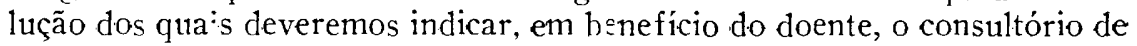
um psicanalista. Tais os casos, por exemplo, em que a libido fixou-se particulamente em certos estadios de desenvolvimento da rersonalidade de tal mane:ra que, a êstes estadios têm tendência a convergir ulteriormente, em determinadas situações, as tendências afetivas do indivíduo Isso porque, regredindo a êstes períodos da vida, por fôrça de um obstáculo penoso que se opõe à sua expansão afetiva integral, tais como certas convenções sociais, algumas personalidades, como nas regressões narcísicas, encontram uma segurança maior.

Em certos casos, por mais que nos esforcemos, falha tôda tentativa psicoterápica, ao mesmo tempo que ficamos com a impressão de que, mesmo com maior convivência, devido a um "recuo do interior" do paciente, não poderemos chegar à compreensibilidade do mecanismo oculto dos distúrbios de seu psiquismo. Não se trata de um sentimento de antipatia que, por vezes, logo à primeira vista, impede nossa sintonização afetiva com determinada pessoa: sentimos contudo que uma barreira intransponível nos separa do consulente, impedindo qualquer penetração afetiva 
e também racional, qualquer tentativa de sintonização e identificação do nosso Eu com o paciente. Nestas circunstâncias, é lícito pensar que um processo extrapsíquico, necessáriamente severo, será responsável pelo desajustamento do psiquimo do cliente. Tal o caso de:

L. D., jovem de 16 anos, filha de armênios. Sem antecedentes hereditários ou pessoais dignos de nota, em plena saúde física, sem conflitos, frustações ou problemas de ordem sentimental, vivendo num ambiente de relativo confôrto, começou a ser invadida sùbitamente por surtos de pavor, de um mêdo atroz, de gênese desconhecida não sòmente de seus familiares como da própria paciente. Em momentos de alegria plena, ou quando estava estudando ou palestrando inteiramente despreocupada, era acometida por receio profundo e indefinido, de pânico mesmo, que a fazia encolher-se a um canto da casa, apavorada, pedindo aflita a presença de seus familiares. Em outras ocsiões, ficava muito apreensiva porque julgava que o sangue havia parado de circular numa determinada região do corpo. Após êsses momentos desfavoráveis, voltava à calma, ao bom estado anterior e, quando parecia que tudo estava resolvido, que havia voltado à normalidade, repetia-se abruptamente tal sintomatologia. Com êsse quadro oligossintomático, veio à nossa presença; baseado nessa noção de incomprecnsibilidade, aplicável a tal caso, aconselhamos a internação, pensando que se tratava dos pródromos de alguma psicopatia, de uma esquizofrenia provàvelmente. Nossa sugestão escandalizou os familiares, que absolutamente não aceitaram tal alvitre. Contudo, decorridos uns quatro meses, voltavam com a doente, cabisbaixos e compungidos, estando ela já a apresentar certo grau de desagregação psíquica, profunda ambivalência e perda do contacto vital, caraterizada por notável autismo.

Rua Iguatcmi, 111 - S. Paulo 